\title{
Brucellosis Testicular Abscess: A Case Report
}

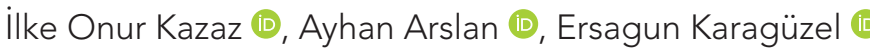 \\ Department of Urology, Karadeniz Technical University School of Medicine, Trabzon, Turkey \\ Cite this article as: Kazaz iO, Arslan A, Karagüzel E. Brucellosis Testicular Abscess: A Case Report. JAREM 2019 ; 9(3): 148-9.
}

\begin{abstract}
Brucellosis is an endemic zoonotic disease that can cause symptoms in multiple organs. Brucellosis is a type of gram-negative coccobacilli. This disease is endemic in the Arabian Peninsula, Mediterranean region, India, and Central and South America. Brucellosis can be caused due to arthritis, orchitis, hepatitis, encephalomyelitis, and endocarditis. It is a multi-organ infectious disease that can cause genitourinary symptoms. Epididymo-orchitis can be seen in $5.7 \%$ of the affected patients. Testicular abscesses associated with brucellosis are very rare. The disease is diagnosed by the presence of orchitis symptoms such as testicular pain, swelling and redness, fever, sweating, serological tests and ultrasonographic findings. Medical treatment, abscess drainage, and orchiectomy can be performed to treat brucellosis. In our study, a rare case of multiple testis abscesses was presented.
\end{abstract}

Keywords: Brucellosis, testicular abscesses, epididymo-orchitis

\section{INTRODUCTION}

Brucellosis is an endemic zoonotic disease caused by Brucella, which are gram-negative coccobacilli. It is endemic in the Arabian Peninsula and the Mediterranean region as well as in India and Central and South America (1). B. abortus, B. melitensis, B. suis, B. ovis, $B$. canis, and $B$. neotomae are the most common Brucella species. These bacteria infect various land and aquatic mammals, including pigs, cows, goats, sheep, dogs, dolphins, whales, seals, and desert grass rats. Humans are accidental hosts of Brucella species (2).

Brucellosis is transmitted to humans via consumption of infected animals (sheep, goat, and pig meat), direct contact with an infected animal, or via inhalation of infectious aerosols.

The disease is frequently manifested by acute symptoms, such as pyrexia, night sweat, arthralgia, myalgia, low back pain, weight loss, fatigue, weakness, headache, dizziness, depression, and anorexia (3). Chronic brucellosis can cause arthritis, orchitis, hepatitis, encephalomyelitis, and endocarditis (2).

Brucellosis is a multi-organ infectious disease and can result in genitourinary issues. Testicular abscess is a rare complication of brucellosis (4). The most common genitourinary issues caused by human brucellosis are epididymo-orchitis, prostatitis, cystitis, interstitial nephritis, pyelonephritis, immunoglobulin A nephropathy, exudative glomerulonephritis, and kidney and testicular abscesses (5). The present study discusses the case of a 42-year-old patient with multiple testicular abscesses, which is rare.

\section{CASE PRESENTATION}

A 42-year-old male was admitted to our clinic with complaints of pain and swelling in his testes. Physical examination of the testes revealed swelling, redness, and pain with palpation. The patient had a history of feeding sheep and consuming cheese prepared from raw milk.

Ultrasonography (US) was performed; results revealed two thickwalled, centrally hypoechoic clusters sized $25 \times 15 \mathrm{~mm}$ and $12 \times 7$ $\mathrm{mm}$ showing peripheral vascularity (abscess), in the lower pole of the left testicle. Blood testing revealed an elevated erythrocyte sedimentation rate and C-reactive protein level. Hemography revealed leukocytosis. After written informed consent was obtained from the patient, he was admitted to the ward. The abscesses in the left testicle were drained together with surgical debridement, and the abscess samples were sent to microbiology laboratory for culturing. B. melitensis was identified in the abscess sample cultures. The patient's blood sample was positive for the Rose Bengal test. The Brucella tube agglutination test from the same blood sample also indicated positive results (titer: 1/640). The patient was started on doxycycline (100 mg twice daily) and rifampicin (600 mg once daily) based on the recommendation of the Department of Infectious Diseases. The dual antibiotic treatment was continued for six weeks. At the end of the sixth week, the patient underwent US; results revealed no sign of abscess or orchitis. The erythrocyte sedimentation rate, C-reactive protein level and leukocyte level were found to be normal based on control blood testing and hemography results.

\section{DISCUSSION}

Brucellosis is an infectious multi-organ disease and is endemic in the Mediterranean region and Arabian Gulf as well as in Mexico and Central and South America (4). Brucellosis is most commonly reported in the slaughterhouse workers, livestock

ORCID IDs of the authors: i.O.K. 0000-0002-2106-0016; A.A. 0000-0001-9779-4297; E.K. 0000-0003-4270-0147. 
breeders, shepherds, and veterinarians as well as in those who consume raw milk or cheese prepared from raw milk (6). The most common clinical manifestations of brucellosis include fever, osteoarticular involvement, and night sweat. The genitourinary system is the second most common site of focal brucellosis occurrence. Epididymo-orchitis is observed in $5.7 \%$ of the affected patients. Testicular abscess associated with brucellosis during the course of epididymo-orchitis infection is very rare (7). In our literature review, we detected nine cases of testicular abscess, six of whom underwent orchiectomy, two underwent abscess drainage, and one underwent only medical treatment (4). Diagnosis is made on the basis of serological test results; US findings; the presence of fever and night sweat; and orchitis symptoms, such as testicular pain, swelling, and redness (1). The presence of Brucella species in the blood culture supported our diagnosis. Multiple samples should always be taken for blood culturing. Persistent bacteremia and positive blood culture are the typical findings of brucellosis (8). In addition to the patient's history and physical examination findings, some tests, such as the Rose Bengal test, Brucella tube agglutination test, Coombs test, and blood culturing, are required for the diagnosis of brucellosis (9). Blood culturing is the gold standard for the diagnosis of brucellosis; however, it is difficult to cultivate the bacteria owing to the long incubation period, them being biosafety level 3 organisms, antibiotic susceptibility, the culture medium, and the need for specialized and experienced personnel $(10,11)$. In chronic cases, the culturing often fails or takes a long time. Blood culture positivity rates are 10\%-20\% in chronic cases $40 \%-70 \%$ in subacute cases (12). Due to these limitations, some serological tests, such as the Rose Bengal test, serum agglutination test (SAT), antiglobulin or Coombs test, microaggluti-

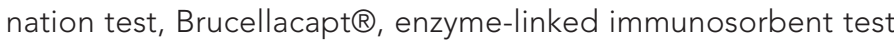
(ELISA), and indirect fluorescent antibody test (IFA) are used (10, 12). The Rose Bengal test is used as a screening test and has a sensitivity rate of approximately $99 \%$. Samples with positive results in the Rose Bengal test should be confirmed using SAT. In the Rose Bengal test and SAT, lipopolysaccharides may show cross-reactivity with gram-negative bacteria, such as Yersinia enterocolitica, Vibrio cholerae, Escherichia coli, and Francisella (13). SAT results higher than 1/160 titer and blood culture positivity are important findings for diagnosis (9). When serum antibodies are present at high levels, i.e., in the condition called the prozone phenomenon, agglutination may be masked and SAT may be negative (12). ELISA, IFA, and polymerase chain reaction are other tests that are rapid and highly sensitive $(10,13)$. The World Health Organization recommends a 45-day treatment with oral doxycycline (200 mg daily) and streptomycin (intramuscularly; $1 \mathrm{~g}$ daily) for the treatment of brucellosis. As an alternative to this treatment recommendation, oral rifampicin (15 mg/kg daily, i.e., 600-800 mg) and doxycycline (200 mg daily) can reportedly be administered for 45 days $(6,9,14,15)$.

\section{CONCLUSION}

In endemic areas, the possibility of brucellosis should not be ignored in the diagnosis of scrotal diseases. Although rare, brucellosis is an important infectious disease that should be considered in cases with testicular abscess.
Informed Consent: Written informed consent was obtained from the patient who participated in this study.

Peer-review: Externally peer-reviewed.

Author Contributions: Concept - I.O.K., A.A., E.K.; Design - I.O.K., A.A., E.K.; Supervision - I.O.K., A.A., E.K.; Resources - I.O.K.; Data Collection and/or Processing - I.O.K., A.A.; Analysis and/or Interpretation - E.K.; Literature Search - A.A.; Writing Manuscript - I.O.K., A.A.; Critical Review - E.K.

Conflict of Interest: The authors have no conflict of interest to declare.

Financial Disclosure: The authors declared that this study has received no financial support.

\section{REFERENCES}

1. Savasci U, Zor M, Karakas A, Aydin E, Kocaaslan R, Oren NC, et al. Brucellar epididymo-orchitis: a retrospective multicenter study of 28 cases and review of the literature. Travel Med Infect Dis 2014; 12: 667-72. [CrossRef]

2. de Figueiredo P, Ficht TA, Rice-Ficht A, Rossetti CA, Adams LG. Pathogenesis and immunobiology of brucellosis: review of Brucellahost interactions. Am J Pathol 2015; 185: 1505-17. [CrossRef]

3. Arapovic J, Spicic S, Ostojic M, Duvnjak S, Arapovic M, Nikolic J, et al. Epidemiological, Clinical and Molecular Characterization of Human Brucellosis in Bosnia and Herzegovina - An Ongoing Brucellosis Outbreak. Acta Med Acad 2018; 47: 50-60.

4. Tahaineh S, Mughli RA, Hakami HI, Al-Faham MI. Conservative treatment for Brucella testicular abscesses: A case report and literature review. Can Urol Assoc J 2015; 9: 679-82. [CrossRef]

5. Bosilkovski M, Kamiloski V, Miskova S, Balalovski D, Kotevska V, Petrovski M. Testicular infection in brucellosis: Report of 34 cases. J Microbiol Immunol Infect 2018; 51: 82-7. [CrossRef]

6. Hizli F, Uygur MC. Brucella orchitis: a rare cause of testicular mass: report of a case. Int Urol Nephrol 2006; 38: 637-9. [CrossRef]

7. Kaya F, Kocyigit A, Kaya C, Turkcuer I, Serinken M, Karabulut N. Brucellar Testicular Abscess Presenting as a Testicular Mass: Can Color Doppler Sonography be used in Differentiation? Turk J Emerg Med 2015; 15: 43-6. [CrossRef]

8. Navarro-Martïnez A, Solera J, Corredoira J, Beato JL, Alfaro EM, Atiénzar M, et al. Epididymoorchitis Due to Brucella mellitensis: A Retrospective Study of 59 Patients. Clinical Infectious Diseases 2001; 33: 2017-22. [CrossRef]

9. Aydemir H, Budak G, Budak S, Celik O, Yalbuzdag O, Keles I. Different presentation types of primary Brucella epididimo-orchitis. Arch Ital Urol Androl 2015; 87: 151-3. [CrossRef]

10. Golshani M, Buozari S. A review of Brucellosis in Iran: Epidemiology, Risk Factors, Diagnosis, Control, and Prevention. Iran Biomed J 2017; 21: 349-59.

11. Kocman EE, Erensoy MS, Tasbakan M, Ciceklioglu M. Comparison of standard agglutination tests, enzyme immunoassay, and Coombs gel test used in laboratory diagnosis of human brucellosis. Turk $J$ Med Sci 2018; 48: 62-7. [CrossRef]

12. Ulu-Kilic A, Metan G, Alp E. Clinical presentations and diagnosis of brucellosis. Recent Pat Antiinfect Drug Discov 2013; 8: 34-41. [CrossRef]

13. Mohseni K, Mirnejad R, Piranfar V, Mirkalantari S. A Comparative Evaluation of ELISA, PCR, and Serum Agglutination Tests For Diagnosis of Brucella Using Human Serum. Iran J Pathol 2017; 12: 371-6.

14. Akinci E, Bodur H, Cevik MA, Erbay A, Eren SS, Ziraman I, et al. A complication of brucellosis: epididymoorchitis. Int J Infect Dis 2006; 10: 171-7. [CrossRef]

15. Stamatiou K, Polyzois K, Dahanis S, Lambou T, Skolarikos A. Brucella melitensis: a rarely suspected cause of infections of genitalia and the lower urinary tract. Braz J Infect Dis 2009; 13: 86-9. [CrossRef] 